\title{
MODELO DE AVALIAÇÃO DE DESEMPENHO GLOBAL PARA INSTITUIÇÃO DE ENSINO SUPERIOR
}

\author{
EVALUATION MODEL OF GLOBAL PERFORMANCE \\ FOR HIGHER EDUCATION INSTITUTIONS
}

\author{
Recebido 10/09/2011 \\ Aceito 15/11/2011 \\ Henrique Martins Galvão ${ }^{1}$, Hamilton Luiz Corrêa² ${ }^{2}$ José Luiz Alves ${ }^{3}$
}

\section{RESUMO}

Este estudo propõe um modelo de avaliação de desempenho global para instituições de ensino superior. É indiscutível a importância das organizações do setor da educação, decisivas para o progresso de uma cidade, região ou país, por serem indutoras do desenvolvimento do conhecimento e da disseminação da informação. Por isso, torna-se necessário desenvolver, para essas instituições educacionais, instrumentos gerenciais de planejamento e de controle que monitorem o desempenho organizacional. Neste caso, uma das tarefas mais relevantes relaciona-se aos tipos de informações que os gerentes necessitam para monitorar e ajustar o desempenho da organização. O modelo de avaliação proposto contribui para melhorar o desempenho organizacional das instituições de ensino, criando valor superior nos serviços oferecidos.

Palavras-chave: Instituições de ensino superior. Avaliação. Desempenho. Indicadores.

\footnotetext{
1 Graduado em Administração e mestre em Administração pela Pontifícia Universidade Católica de São Paulo (PUCSP). Professor e coordenador do curso de Administração na Fatea (Rede Salesianas). E-mail: hmgalvao@usp.br

2 Professor Doutor do Departamento de Administração da Universidade de São Paulo (USP). E-mail: hamillco@usp.br

3 Graduado em Pedagogia e mestre em Educação pelo Centro Universitário Salesiano de São Paulo. Professor e coordenador pedagógico na Fatea (Faculdades Integradas Teresa D’Ávila). E-mail: coord_fatea@fatea.br
} 


\section{ABSTRACT}

This study proposes a model to evaluate overall performance for Higher Education Institutions. It is unquestionable the importance of organizations from the education sector for knowledge development and dissemination of information, necessary for the progress of a city, region or country. However, it is necessary to develop tools for planning and management control to monitor organizational performance. In this case, one of the most important tasks is related to the types of information that managers need to monitor and tune the performance of the organization. The proposed evaluation model helps to improve the organizational performance of education institutions, creating higher value in the services offered.

Keywords: Higher education institutions. Evaluation. Performance. Indicators.

\section{INTRODUÇÃO}

A dinâmica do ambiente induz as organizações à complexidade e os executivos responsáveis pela gestão empresarial a possuir capacidade e habilidades para fixar metas e objetivos, os quais possam ser medidos com eficiência e eficácia. Este estudo propõe o desenvolvimento de um modelo global de avaliação de desempenho para Instituições de Ensino Superior (IES) no Brasil. O modelo vigente de avaliação para as organizações do setor da educação é baseado no Sistema Nacional de Avaliação do Ensino Superior (Sinaes) (Lei n. 10.861, de 14 de abril de 2004), e para efeito deste estudo, também serão considerados outros modelos de avaliação de desempenho organizacional, tais como: o Modelo de Excelência da Gestão (MEG), da Fundação Nacional da Qualidade; o Prêmio Americano de Qualidade Malcolm Baldrige (BNQP); o Sigma Sustainbility; e o Balanced Scorecard.

As instituições de ensino superior, notadamente as organizações privadas, sofrem a intervenção do Estado, que exerce a prerrogativa constitucional de autorizá-las (Constituição da República Federativa do Brasil, 1988, Artigo 209, inciso I). Evidencia-se, nesse caso, a especificidade do setor no preparo e formação de profissionais que suprirão as demandas do mercado, para compor os quadros funcionais empresariais. O desenvolvimento tecnológico e científico de um país ou região está atrelado à capacidade com que as organizações do setor desenvolvem seu processo de formação dos futuros profissionais. Atribui-se, neste caso, a responsabilidade do governo e dessas instituições à busca constante de melhor qualidade de ensino. Desse modo, a intervenção do governo em determinar políticas de avaliação de desempenho das IES tem sido constante e encarada como prioridade.

Como questionamento, cabe verificar se o sistema de avaliação fundamentado no Sinaes é o único modelo ou se outras propostas trariam contribuições mais proveitosas, inclusive concorrendo para enfrentar os desafios da elevada concorrência no setor. O objeto geral deste estudo é propor um modelo alternativo de avaliação global de desempenho às instituições de ensino superior do setor privado. Quanto aos objetivos específicos, este estudo analisa e identifica como os modelos de avaliação, enunciados acima, são empregados para a melhoria da gestão das organizações. Quanto à metodologia, utilizou-se a pesquisa exploratória, descritiva, optando-se pela estratégia de pesquisa do tipo bibliográfica e documental. Após a realização do estudo e comparações dos modelos de avaliação, foi elaborado o modelo, corroborando os objetivos, de forma a contribuir para a melhoria do desempenho das organizações educacionais e aprofundar estudos em novos modelos. 


\section{FUNDAMENTAÇÃO TEÓRICA}

\subsection{Avaliação de desempenho organizacional}

Tomar decisões em um ambiente competitivo e de forte pressão exige dos executivos a capacidade para o planejamento e controle do negócio. Os níveis organizacionais devem responder, com agilidade e flexibilidade, ao processo de comunicação e tomada de decisão. Por outro lado, a tomada de decisão pode não ser tarefa fácil, pois a empresa é um organismo dinâmico que interage constantemente com o ambiente. Mañas (1993) ressalta que os executivos devem buscar uma ação coordenada que proporcione o aumento da competitividade, incentivando inovações e melhorias no ambiente organizacional, além da busca de novas oportunidades para que a empresa conquiste vantagens competitivas diante dos concorrentes. Para Drucker (1999), os executivos responsáveis pela gestão empresarial devem possuir capacidade e habilidades para remover as barreiras internas, praticando políticas de incentivos e programas de melhoria em toda estrutura da empresa e tornando possível a confiança e o compartilhamento de ideias.

Esses aspectos reforçam a adoção da avaliação do desempenho organizacional para o gerenciamento dos negócios da empresa. A utilização de técnicas para medir e monitorar o desempenho organizacional é crítica, e o processo de tomada de decisão requer qualidade e agilidade das informações. Yokomizo (2009) explica que a avaliação de desempenho consiste no estabelecimento de modelos de avaliação, os quais induzem à definição de planos de ação associados aos principais processos organizacionais.

Existem vários motivos que levam as organizações a optar pelo uso de medidas de desempenho organizacional, como, por exemplo, a comparação do desempenho com os concorrentes ou de organizações de outros setores, o que possibilita a verificação periódica do cumprimento das estratégias de curto, médio ou longo prazo. Para Corrêa (2010), uma organização, ao adotar um modelo de avaliação de desempenho organizacional, deve se preocupar se o modelo proposto responde às seguintes perguntas: "para quê"; "para quem"; "o quê"; "como"; "quem" e "quando". Essas indagações auxiliarão na compreensão da finalidade das dimensões e dos conjuntos de indicadores sugeridos, bem como definirão quem os usará, qual o conteúdo, quais os passos de desenvolvimento e de implantação e qual a frequência da aplicação. Além disso, a avaliação de desempenho organizacional deve incluir as variáveis e dimensões que causam algum efeito no alcance dos objetivos fixados no planejamento estratégico. Desse modo, a avaliação de desempenho deve refletir uma relação de causa e efeito, ou seja, o resultado de uma avaliação não deve ter implicação em uma área específica da organização, mas no processo de interação entre as áreas organizacionais. A representação das relações de causa e efeito entre os objetivos pode ser realizada por meio do mapa estratégico.

Kaplan e Norton (2001 apud HOURNEAUX JR.; CORRÊA, 2007) explicam que o conjunto de indicadores permite descobrir modos diferentes para auxiliar a organização a alcançar os objetivos previamente determinados no planejamento estratégico. Ressalta-se que o uso dos indicadores precisa ser encarado como tarefa primordial e não pode se tornar mera e simples atividade. Ainda assim, os indicadores implicam grande impacto sobre a cultura organizativa e sobre os responsáveis por defini-los e utilizá-los na organização. Melhor dizendo, a forma como os critérios e os modos são executados repercute na aceitação positiva ou negativa do sistema de avaliação.

De acordo com Bowersox (2001), existem indicadores de medida baseados em atividades ou funcionais e indicadores orientados para o processo, os quais são mais apropriados ao ambiente competitivo. Todavia, os executivos podem, ainda, fazer uso de indicadores de desempenho externo. Também, para efeito de verificação de seu desempenho, a empresa pode utilizar o benchmarking, que permite, comparando instituições, avaliar as melhores práticas e 
processos e o desempenho. Whiteley (1999) explica que a empresa precisa conhecer e identificar os seus processos. Por exemplo, os processos de distribuição envolvem o processo de vendas, o processo de faturamento e o processo de atendimento. Desse modo, a empresa pode utilizar indicadores globais de desempenho, para avaliar e controlar as atividades durante todo o processo.

Hourneaux Jr., Cunha e Corrêa (2004) afirmam que existem algumas metodologias para medir o desempenho das organizações, tais como: Balanced Scorecard, Tableau de Jour, Prêmio Americano de Qualidade, Sigma Sustainbility e Prêmio Nacional da Qualidade. As metodologias compreendem modelos de avaliação de desempenho da organização e combinam medidas financeiras e não financeiras, as quais são capazes de contribuir, de forma significativa, para a melhoria do desempenho e competitividade organizacional.

\subsection{Prêmio americano de qualidade Malcolm Baldrige (BNQP)}

O Baldrige National Quality Program (BNQP) consiste em um programa que visa promover conhecimento para organizações de todos os tamanhos que desejam compartilhar as melhores práticas de gestão e alcançar níveis mais altos de desempenho. Está direcionado para os setores da educação, saúde, indústria, organizações sem fins lucrativos, governo e pequenas empresas (Nist, 2010). O programa é representado por critérios ou dimensões que constituem a base das avaliações das organizações e fornecem feedback do desempenho da organização. Os critérios para excelência no desempenho servem como modelo integrado com os resultados alcançados e como ferramenta para avaliar esforços de melhoria. O modelo de avaliação gera um relatório de feedback, destacando forças e oportunidades, e baseia-se em sete critérios (ou dimensões) direcionados para áreas-chave: 1. liderança; 2. planejamento estratégico; 3. ênfase no cliente; 4. mensuração de desempenho, análise e conhecimento gerencial; 5. ênfase na força de trabalho; 6 . gestão de processos; e 7 . resultados.

Esses critérios desempenham quatro papéis importantes para a competitividade e fortalecimento das organizações: 1. ajudar a melhorar o desempenho das práticas organizacionais, das capacidades e dos resultados; 2 . facilitar a comunicação e compartilhamento das informações sobre as melhores práticas em organizações de todos os tipos (benchmarking); 3. servir como ferramenta de trabalho, compreensão e desempenho da administração; e 4. guiar o planejamento organizacional e gerar oportunidades para a aprendizagem (BNQP, 2010). O diagrama da figura 1 demonstra que o modelo é sistêmico e seis critérios definem as operações para alcance dos resultados.

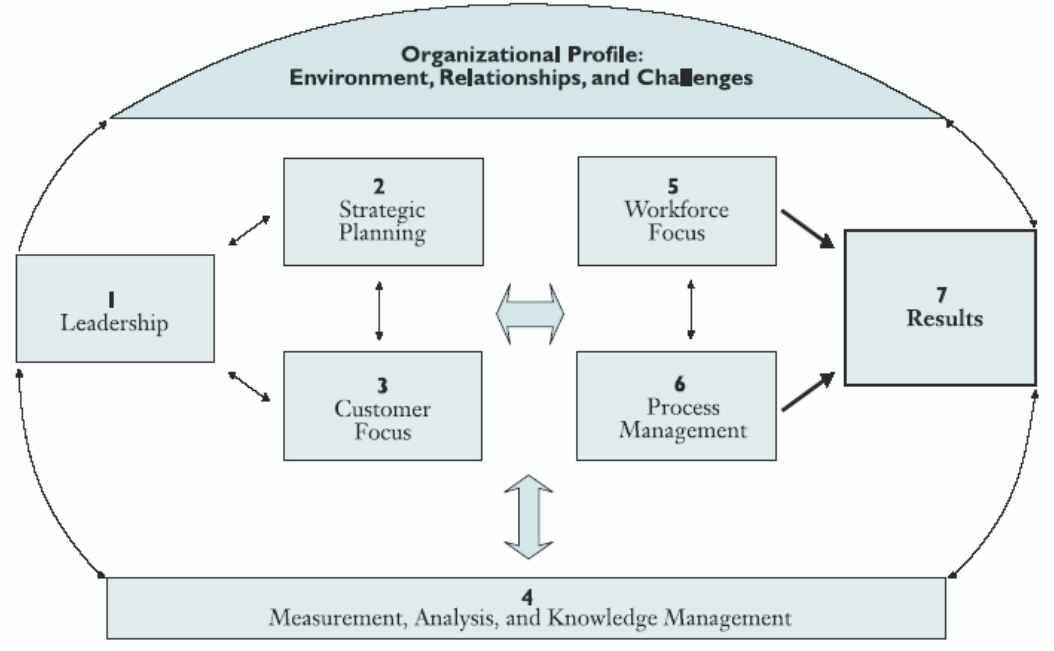

Figura 1 - Quadro da excelência de desempenho

Fonte: <http://www.nist.gov/baldrige/>. 
Os itens 1, 2 e 3 representam o esforço na direção de oportunidades futuras. Os itens 5, 6 e 7 representam as atividades (operações) e os resultados do desempenho global. O item 4 é crítico para o gerenciamento da organização - gera base de conhecimento para melhoria do desempenho e competitividade. Para cada um dos sete critérios, ocorrem desdobramentos em itens de desempenho que são avaliados e determinam pontuação dentro do limite previamente estabelecido. A maior pontuação é registrada com base nos "resultados", que oferecem feedback ao candidato, sintetizado em dois grupos: processo e resultados. O grupo "processo" se refere aos métodos que a organização usa e às melhorias adotadas para tratar os requisitos dos critérios de 1 a 6 , e que convergem para quatro fatores que resumem o processo: abordagem, desenvolvimento, conhecimento e integração. O grupo "resultados" indica o nível de desempenho atual, as tendências de sustentabilidade de desempenho, as comparações de desempenho e a integração dos indicadores com os resultados dos clientes, produtos, mercado e processos importantes.

\subsection{European Foundation for Quality Management (EFQM)}

O European Foundation for Quality Management (EFQM), como o programa americano, apoia e estimula a gestão das empresas e, quando necessário, auxilia os países da Comunidade Europeia a melhorar o seu desempenho (EFQM, 2010). Trata-se de uma ferramenta para avaliar a maturidade da organização, melhorando seu desempenho e ganhando reconhecimento. A metodologia é constituída por nove critérios, que não são prescritivos. Cinco deles correspondem a "Capacitadores" (Meios) e quatro a "Resultados". Na figura 2, as setas enfatizam a natureza dinâmica do modelo, mostrando inovação e aprendizagem, que contribuem para melhorar os resultados. Os resultados excelentes estão associados ao desempenho dos clientes, das pessoas e da sociedade, os quais são alcançados pela liderança que conduziu a estratégia. A transferência da estratégia, a partir da liderança organizacional, é transferida por meio das pessoas, das parcerias e recursos e dos processos.

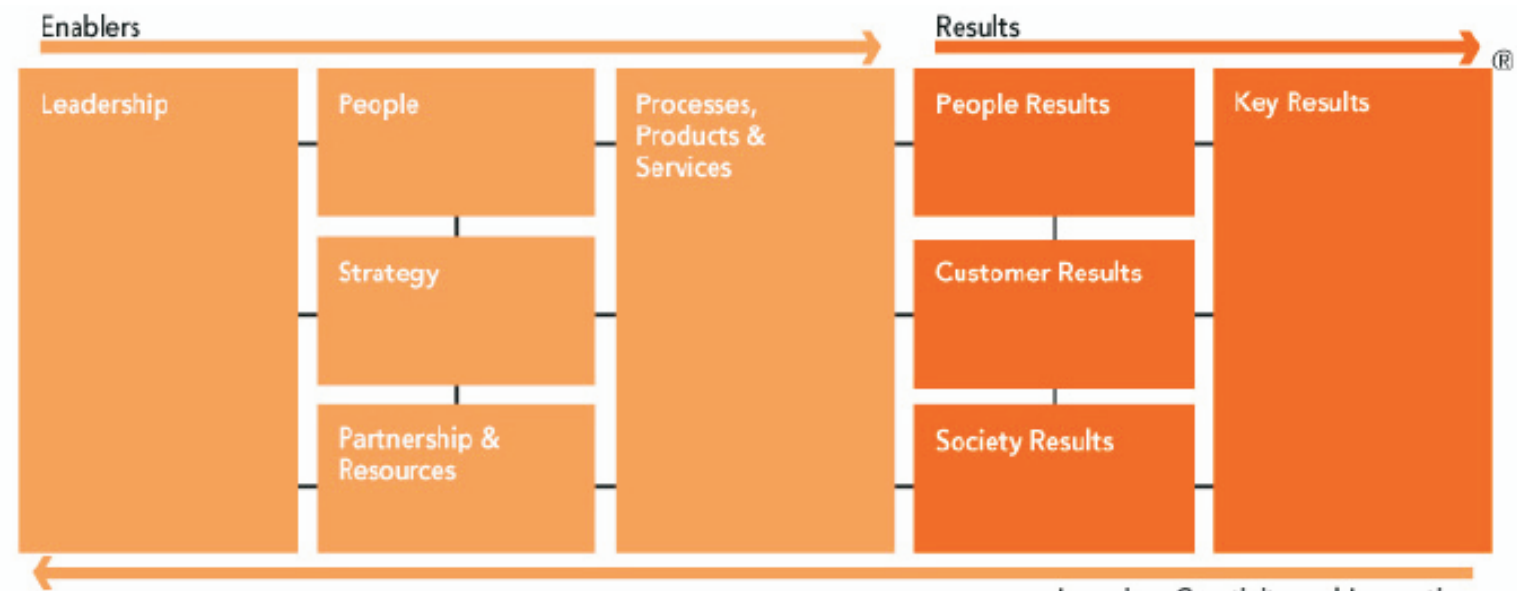

Figura 2 - Diagrama EFQM: pontuações entre os critérios

Learning, Creativity and Innevation

Fonte: European Quality Award. Disponível em: <http://www.efqm.org>.

O modelo europeu da qualidade, assim como o modelo americano, atribui significativa pontuação aos "Resultados". Os resultados com clientes certificam que a organização busca medir e alcançar resultados relevantes em relação aos clientes - indicadores de percepção e de 
desempenho. Os resultados com as pessoas verificam se a organização busca medir e alcançar resultados relevantes em relação às pessoas. Os resultados com a sociedade sugerem que a organização tem alto desempenho e fixam indicadores de desempenho relevantes para a sociedade. Os resultados-chave verificam se a organização atua de forma abrangente e alcança os objetivos dos elementos-chave de sua política e estratégia.

Para efeito de se conhecer o estágio do desempenho da organização, o modelo EFQM utiliza-se de um "radar". Processo semelhante ao proposto no modelo americano, o "radar" consiste em um instrumento que indica, com precisão, os resultados a serem alcançados, que são decorrentes das estratégias estabelecidas e que espelham o desempenho da organização em seus processos, sem esquecer a satisfação das necessidades de todas as partes interessadas. Assim, é possível verificar se a organização planeja e desenvolve um conjunto integrado de abordagens que permitam alcançar os resultados desejados, no presente e no futuro.

\subsection{Fundação Nacional da Qualidade (FNQ): modelo de excelência da gestão}

A Fundação Nacional da Qualidade (FNQ), instituição sem fins lucrativos, criada em 1991, é a responsável por organizar, promover e avaliar o Prêmio Nacional da Qualidade ${ }^{\circledR}$ (PNQ). O PNQ representa o reconhecimento das melhores práticas de excelência em gestão desempenhadas pelas organizações no Brasil (FNQ, 2010). O Modelo de Excelência em Gestão, apresentado na figura 3, está estruturado com base em 11 fundamentos: pensamento sistêmico; aprendizado organizacional; cultura de inovação; liderança e constância de propósitos; orientação por processos e informações; visão de futuro; geração de valor; valorização das pessoas; conhecimento sobre o cliente e o mercado; desenvolvimento de parcerias; e responsabilidade social. Esses fundamentos são colocados em prática por meio de oito critérios: 1. liderança; 2. estratégias e planos; 3. clientes; 4. sociedade; 5. informações e conhecimento; 6. pessoas, 7. processos; e 8. resultados.

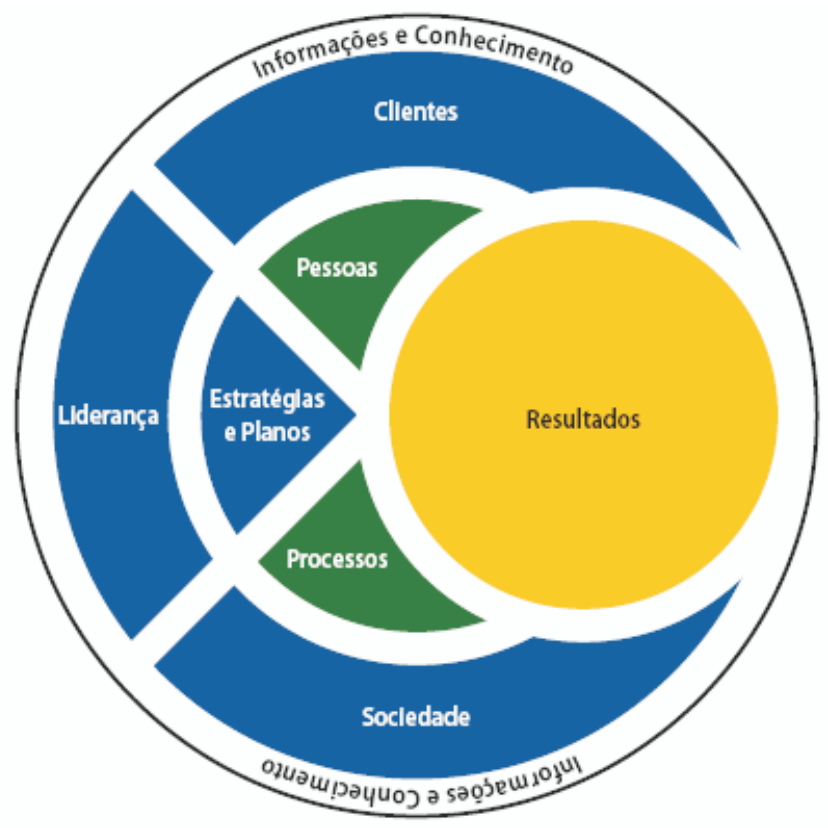

Figura 3 - Modelo de Excelência da Gestão (MEG): visão sistêmica Fonte: FNQ: critérios de excelência (2010).. 
No diagrama da figura acima, estão indicados aspectos que são tangíveis, expressos em medidas quanti ou qualitativas, por meio de requisitos presentes em questôes formuladas e em solicitações de informações específicas. Estas, por sua vez, são agrupadas em itens, correspondentes a cada um dos oito critérios mencionados. O objetivo dessa distribuição é facilitar o entendimento de conteúdos afins considerados no modelo e reproduzir, de forma lógica, a condução de temas essenciais a uma organização. A figura 3, que representa o MEG, sugere uma visão sistêmica da gestão organizacional, apresenta características de flexibilidade e não visa a prescrição de ferramentas ou práticas de gestão. Nesse sentido, o modelo é vantajoso para organizações de todos os tipos, pois possibilita aplicar avaliação e diagnóstico, bem como orientar ações.

\subsection{Sigma Sustainbility}

O Sigma Sustainbility teve origem na Grã-Bretanha quando do lançamento do Projeto Sigma, em 1999. O modelo foi revisado em 2003 e consiste em um conjunto de diretrizes e instrumentos que avaliam a capacidade da organização em termos de desempenho das atividades. O feedback dos resultados traz diagnóstico dos dilemas, ameaças e oportunidades nos campos econômico, social e ambiental. As normas e procedimentos do Projeto Sigma proporcionam soluções flexíveis e viáveis, que possibilitam implementações em vários tipos de organizações e setores (SIGMA, 2010).

Os princípios do Sigma Sustainbility consistem em dois elementos centrais: o gerenciamento holístico e o exercício de práticas sustentáveis. No primeiro caso, o Sigma integra abordagem para o capital ambiental, humano, social, industrial e capital financeiro. No segundo caso, dispõe sobre o exercício da responsabilidade, de modo transparente e responsável com todos os stakeholders, em concordância com regras e padrões. A caixa de ferramentas objetiva o aconselhamento e orientação dos desafios gerenciais, além de fornecer inúmeros instrumentos que auxiliam na melhoria do gerenciamento de problemas de sustentabilidade e do desempenho geral.

O Sigma Sustainbility não tem, a princípio, caráter prescritivo de desempenho, uma vez que é útil para auxiliar as organizações na definição dos objetivos e metas de desempenho. Também oferece oportunidades para solucionar qualquer tipo de dificuldade. Entretanto, as suas diretrizes funcionam como procedimentos normatizadores e orientadores para prescrever níveis mínimos de desempenho. A estrutura de gerenciamento trata dos problemas de sustentabilidade relacionados aos principais processos e instâncias decisórias da organização. Conforme se observa na figura 4 , baseia-se em um ciclo de quatro fases flexíveis e desdobradas em subfases: 1. liderança e visão; 2. planejamento; 3. realização; e 4. revisão, feedback e informação.

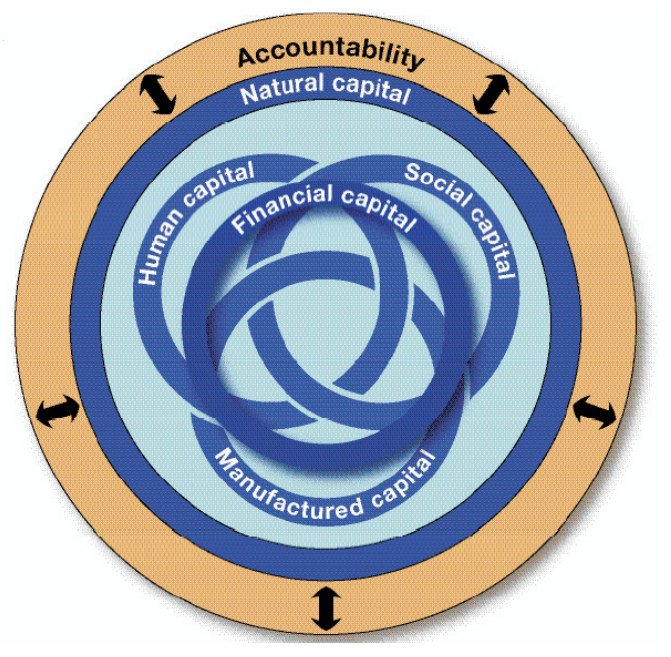

Figura 4 - The Sigma Guiding Principles Fonte: Sigma: The Sigma Guideliness (2010). 
O Projeto Sigma é flexível e compatível para se integrar com outros padrões, como a ISO 14.001, ISO 9.000, o OHSAS 18.001 e o AA 1.000. Ele permite acesso a: ferramenta de contabilidade ambiental; Global Reporting Initiative (GRI); e ferramenta de marketing e sustentabilidade. Também é útil como guia de risco, de oportunidade e de sustentabilidade, bem como serve de diretriz e norma relevante para o desenvolvimento sustentável.

\subsection{Balanced Scorecard (BSC)}

O modelo de avaliação de desempenho Balanced Scorecard (BSC), criado Kaplan e Norton, é uma ferramenta poderosa de avaliação. Sua utilização é justificada para mensurar o desempenho da organização e se concentra na gestão da elaboração e desenvolvimento da estratégia da organização, a partir da missão, visão, objetivos, iniciativas e indicadores (KAPLAN; NORTON, 2006). O BSC baseia-se em quatro perspectivas, e sua aplicação permite criar valor para o acionista. Cada perspectiva está ligada a uma cadeia de relações de causa e efeito: financeira - formaliza objetivos financeiros e associa com a estratégia de crescimento em termos de lucratividade, rentabilidade e retorno para acionistas; cliente - está associada à capacidade da organização na criação de valor e diferenciação; processos internos - visa a utilização dos recursos necessários para os negócios, bem como a capacidade da organização em melhorar o nível de qualidade e de satisfação de clientes e acionistas; e aprendizado e crescimento - deve proporcionar cultura para o crescimento, inovação e flexibilidade para mudanças organizacionais.

De acordo com Hourneaux Jr., Cunha e Corrêa (2004), os indicadores se interrelacionam com cada uma das quatro perspectivas, devendo ser escolhidos em conformidade com a visão, a missão e a estratégia e desdobrados hierarquicamente. Outro aspecto relevante ocorre em face das metas de desempenho, dos indutores de desempenho e dos indicadores de causa e efeito. Os indicadores são classificados por tipo de resultado (ocorrência) e de desempenho (tendências). Os indicadores de resultados estão ligados à perspectiva financeira, como, por exemplo, a lucratividade, o market share e o índice de satisfação dos clientes. Os indicadores de desempenho mostram o sentido de direção e a estratégia, refletindo o sucesso ou fracasso, em termos das ações que são desenvolvidas.

A figura 5 apresenta as perspectivas do Balanced Scorecard.

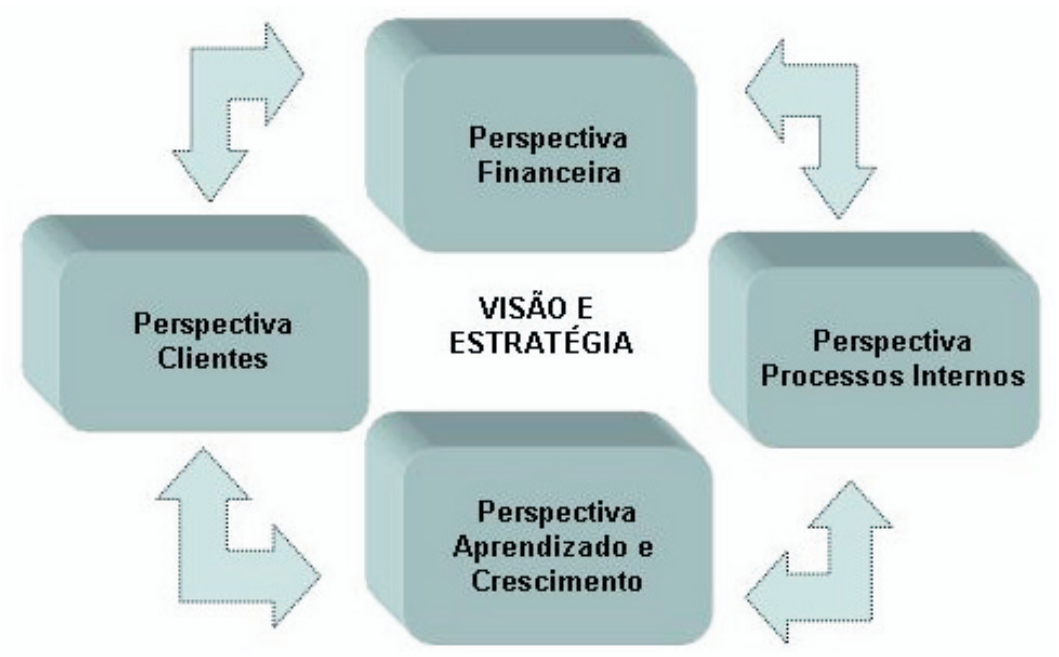

Figura 5 - Persperctivas do Balanced Scorecard

Fonte: adaptado de Cunha, Corrêa e Calegari (2007). 
Kaplan e Norton (2006) afirmam que o processo inicia-se a partir da definição da proposta de valor pela alta direção, essencial para gerar sinergias entre as áreas operacionais, unidades de apoio e stakeholders externos. Contudo, o mapa estratégico da organização e o BSC auxiliam na identificação e esclarecimentos das prioridades e no modo como a comunicação é desencadeada por toda a organização. O BSC contribui para que a organização realize o alinhamento dos processos-chave com a estratégia e tem a vantagem de traduzir a estratégia em uma linguagem operacional e levar à sua prática diária, envolvendo toda a organização. Por outro lado, o BSC faz com que a estratégia se torne uma atividade contínua no acompanhamento dos processos e proporcione aprendizagem e adaptação da organização.

Cunha, Corrêa e Calegari (apud KAPLAN; NORTON, 2006) explicam que o BSC tem a vantagem de ser utilizado como sistema de controle estratégico, permitindo a mensuração dos indicadores. Entretanto, observa-se que o BSC dedica muita importância à missão, à visão e à estratégica, as quais podem gerar dificuldades de implantação e certo grau de complexidade para sua operacionalização. Além disso, não prevê uma perspectiva de responsabilidade socioambiental empresarial, como o Sigma Sustainbility.

\subsection{Sistema Nacional de Avaliação da Educação Superior (Sinaes)}

O Sinaes foi criado pela Lei $n^{\circ} 10.861$, de 14 de abril de 2004, e consiste no novo sistema de avaliação das instituições de educação superior conduzido pelo MEC/Inep. Está sob a coordenação e supervisão da Comissão Nacional de Avaliação da Educação Superior (Conaes), que mantém articulação com a SESu, o Semtec, o Inep e a Capes, órgãos constituídos do poder executivo, desempenhando o papel de garantir o processo de avaliação (BRASIL, 2009). O principal objetivo do Sinaes é fomentar a cultura da melhoria da qualidade da educação, direcionar a expansão da oferta do ensino, contribuir para o efetivo aumento da eficácia institucional, acadêmica e social. O novo sistema também visa aprofundar os compromissos com as responsabilidades sociais (BRASIL, 2005). A sistemática de avaliação aborda três instrumentos avaliativos e aplicados em momentos diferentes: Avaliação das Instituições de Educação Superior (Avalies); Avaliação dos Cursos de Graduação (ACG); e Exame Nacional do Desempenho dos Estudantes (Enade).

O Sinaes adota procedimentos que incluem os aspectos relativos ao ensino, à pesquisa e à extensão, consolidados em documentos institucionais: Plano de Desenvolvimento Institucional (PDI), Projeto Pedagógico Institucional (PPI), Projetos Pedagógicos dos Cursos (PPCs), Comissão Própria de Avaliação (CPA), Relatório de Avaliação Interna (CPA) e Cadastro de Docentes. O processo de avaliação, no âmbito do Sinaes, tem início a partir do Enade, cujos conceitos variam de 1 a 5 e constituem indicadores prévios da situação do curso em vista da renovação de reconhecimento. O conceito 1 ou 2 implica a visita da comissão avaliadora, enquanto com os conceitos 3, 4 ou 5 a IES pode optar por receber ou não a visita de avaliação e adotar o conceito como permanente do curso (CC) (MEC, 2009).

De acordo com a Portaria no. 12, de 5 de dezembro de 2008, o Índice Geral de Cursos (IGC) é o indicador de qualidade da IES. Sua composição consiste na média ponderada dos CPC e de dados sobre a pós-graduação (MEC, 2009). O IGC varia de 1 a 5 e serve de balizador para os processos de avaliação in loco das IES. Do mesmo modo que o CPC gera o CC, o IGC gera o Conceito Institucional $(\mathrm{Cl})$. Os procedimentos avaliativos do Sinaes, a avaliação institucional externa in loco, para o processo de recredenciamento da IES, independe do IGC e segue a ordem de avaliação de cursos no Enade (conceito Enade e CPC) e a divulgação dos conceitos de curso (CC). Após a visita in loco da comissão avaliadora, é divulgado o $\mathrm{Cl}$, por meio das 
secretarias vinculadas ao MEC (SESu, Setec e Seed), bem como por decisões e procedimentos de regulação. Cabe ressaltar que o $\mathrm{Cl}$ é um conceito resultante da avaliação institucional, baseada em um conjunto de dez dimensões definidas pela Conaes.

A tabela 1 apresenta as dimensões de avaliação de uma instituição de ensino superior.

Tabela 1 - Dimensões de avaliação

\begin{tabular}{|c|c|c|}
\hline Dimensão & $\begin{array}{c}\text { Qtd } \\
\text { Indicadores }\end{array}$ & Pesos \\
\hline 1-Misão e Deservolvimento Institucional. & 2 & 5 \\
\hline $\begin{array}{l}\text { 2-As políticas para a pesquisa, a pós-graduação, a extensão e as respectivas nomas de } \\
\text { operacionalização, incluindo os estímulos para a produçăo acadêmica, para as bolsas de } \\
\text { pesquisa, de monitoria e demais modalidades. }\end{array}$ & 7 & 35 \\
\hline $\begin{array}{l}\text { 3-A resporsabilidade social da instituição, considerada especialmente no que se refere em } \\
\text { sua contrbuição à inclusão social, ao deservolvimento econômico e social, à defesa do } \\
\text { meio ambiente, da memória cultural, da produção artística e do patrimônio cultural. }\end{array}$ & 4 & 5 \\
\hline 4A comuricação com a sociedade. & 3 & 5 \\
\hline $\begin{array}{l}\text { 5-As políticas de pessoal, de carreira do corpo docente e técrico-administrativo, seu } \\
\text { aperfeiçoamento, seu deservolvimento profissional e suas condiçóes de traballo. }\end{array}$ & 6 & 20 \\
\hline $\begin{array}{l}\text { 6-Organização e gestão da instituição, especialmente o funcionamento e } \\
\text { representatividade dos cole giados, sua independência e autonomia na relação com a } \\
\text { mantenedora, e a participaça dos segmentos da comunidade universitária nos processos } \\
\text { decisónios. }\end{array}$ & 4 & 5 \\
\hline $\begin{array}{l}\text { 7-Infra-estrutura fisica, especialmente a de ensino e de pesquisa, biblioteca, recursos de } \\
\text { informação e comunic ação. }\end{array}$ & 5 & 10 \\
\hline $\begin{array}{l}\text { 8-Planejamento e avaliação, especialmente em relação aos processos, resultados e eficácia } \\
\text { da auto-avaliação institucional. }\end{array}$ & 3 & 5 \\
\hline 9-Políticas de atendimento ao estudante. & 4 & 5 \\
\hline $\begin{array}{l}\text { 10-Sustentabilidade finarceira, tendo em vista o signific ado social da continuidade dos } \\
\text { compromissos na oferta da educação superior. }\end{array}$ & 3 & 5 \\
\hline
\end{tabular}

Fonte: Brasil (2009).

Cada uma das dimensões representa atividades-fim da educação e atividades-meio que dão suporte para que as atividades-fim sejam alcançadas, conforme formalizado nos documentos de planejamento da instituição, como PDI e PPI. As atividades-fim são representadas pelo ensino, pesquisa e extensão. Cada dimensão é desdobrada em indicadores que são pontuados segundo referência pré-estabelecida. As referências reduzem a subjetividade do avaliador e estabelecem padrões de avaliação.

\section{METODOLOGIA DE PESQUISA}

A metodologia de pesquisa adotada para este trabalho é de caráter exploratório, descritivo, baseado em levantamento bibliográfico que utilizou uma série de fontes secundárias, como publicações em livros, artigos científicos de revistas eletrônicas e sites especializados, de âmbi- 
to nacional. A construção do modelo de avaliação de desempenho global tem como base os modelos inicialmente apresentados e, respectivamente, fundamentados. Espera-se que o modelo de avaliação desenvolvido neste estudo traga reflexões e contribuições para a melhoria do desempenho das organizações educacionais e para o aprofundamento de estudos de novos modelos.

\section{MODELO DE AVALIAÇÃO DE DESEMPENHO GLOBAL PARA IES}

Os modelos de avaliação de desempenho apresentados oferecem contribuições para a elaboração do modelo proposto. Os modelos baseados no FNQ, BNQP e EFQM oferecem os princípios da excelência e padrões de qualidade com foco na estratégia, nos processos e nos resultados. O modelo Sigma Sustainbility enfoca o ambiental e o social, e o BSC se concentra no desenvolvimento do planejamento estratégico como ponto fundamental para a construção da visão e da missão manifestadas em todos os processos. O modelo de avaliação do Sinaes revela a amplitude de atuação das instituições de ensino e os motivos da existência das atividades-meio que sustentam as atividades-fim. O processo de construção do modelo parte da formulação da visão e missão para elaboração do planejamento estratégico e dos objetivos estratégicos. O processo sistêmico define as dimensões, o conjunto de indicadores de desempenho e as metas, que, quando colocados em prática, são retroalimentados, como se pode observar na figura 6.

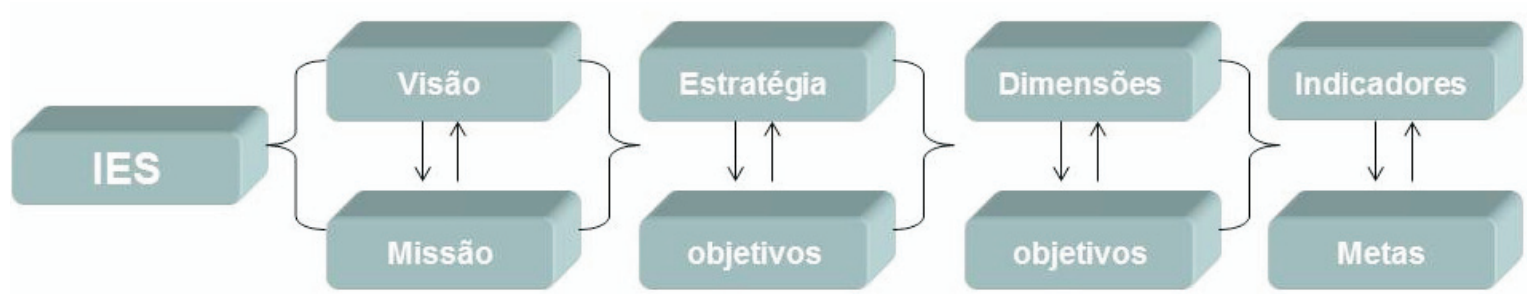

Figura 6 - Desdobramento da visão e missão Fonte: elaborada pelos autores.

Organizações do setor educacional, tais como as faculdades, isoladas e privadas, apresentam características peculiares e sofrem forte regulação do governo. Para além da dimensão financeira, a sobrevivência da organização educacional depende da qualidade de ensino. $O$ alcance de melhores níveis de desempenho do processo de ensino-aprendizado depende de como ocorre o desdobramento da estratégia nos diversos níveis da estrutura organizacional e os efeitos no desempenho do corpo técnico-administrativo, do corpo docente e do corpo discente. De outro modo, a organização pode ter implicações ao atender aos propósitos do ensino, da pesquisa e da extensão. A combinação das oito dimensões determina a capacidade da organização de melhorar seus processos e dar respostas rápidas às pressões ambientais. Neste caso, o desempenho é examinado com base na dimensão de resultados. O desempenho da organização deve ser avaliado e comparado e desencadear o processo de retroalimentação, com base na dimensão da aprendizagem e crescimento, apresentados na figura 7, para examinar seus processos, rever indicadores e metas, em busca da melhoria da gestão organizacional, e para oferecer serviços de nível elevado. 


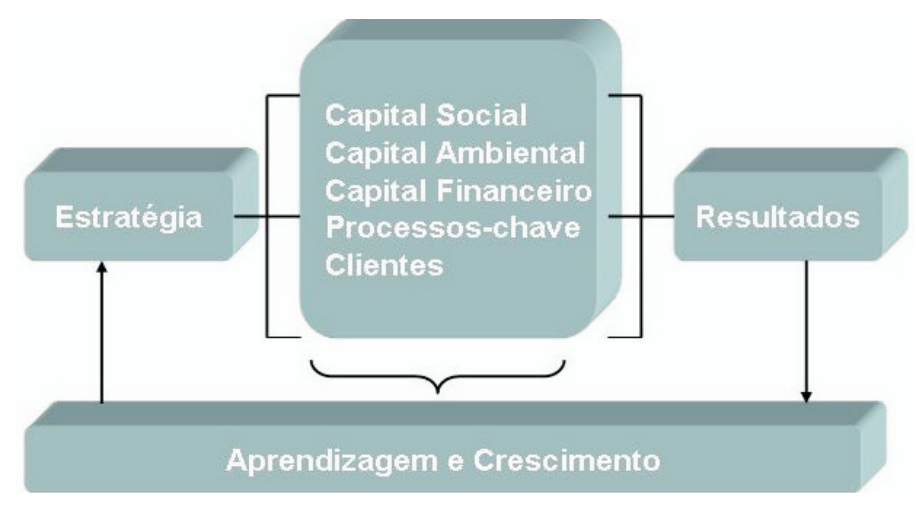

Figura 7 - Elementos centrais do modelo de avaliação de desempenho Fonte: elaborada pelos autores.

O modelo de avaliação de desempenho da IES, aqui proposto, está estruturado em oito dimensões que se interligam, conforme apresentado na tabela 2.

Tabela 2 - Dimensões do modelo de avaliação

Estratégia: representa a capacidade da alta direção em exercer a liderança sobre o ambiente interno, para gerar sinergias e criar valor. Inclui o sistema de governança e se define o Projeto de Desenvolvimento Institucional (PDI), o Projeto Pedagógico Institucional (PPI) e o Regimento Interno (RI).

Capital social: enfoca a capacidade dos corpos técnico, administrativo, docente e discente de desempenhar as atribuições alinhadas com os objetivos estratégicos e em consonância com os objetivos táticos e operacionais. O ambiente organizacional deve ser encorajador, para assegurar o cumprimento das metas. Verificam-se as contribuições das políticas associadas aos padrões OHSAS 18.001 e SA 8.000.

Capital ambiental: indica o compromisso da organização com o uso sustentável dos recursos naturais, inclusive com seus fornecedores e clientes, como o estabelecimento de políticas, programas e procedimentos para a coleta, armazenamento, reciclagem e descarte de resíduos originários de suas operações.

Capital financeiro: inclui a transparência e a ética nas informações econômico-financeiras, como a elaboração das políticas de crédito e cobrança, procedimentos contábeis, plano orçamentário e de investimentos em infraestrutura e a utilização dos indicadores econômicos.

Processos-chave: associados aos objetivos do negócio e destaque para as atividades de apoio, que se refereme às áreas funcionais, como, por exemplo, secretaria acadêmica, financeiro, marketing, coordenações, núcleos e infraestrutura. O desempenho dessa dimensão pode afetar a continuidade da organização em termos dos resultados financeiros e no cumprimento das políticas de regulação do ensino superior.

Clientes: a elaboração e definição dos objetivos, indicadores e metas estão associadas, em sua maior parte, com as atividades que conduzem ao melhor desempenho dos alunos. O desempenho das atividades de apoio e atividades-fim influencia a percepção dos discentes quanto à qualidade da IES e pode impactar nos resultados.

Aprendizagem e crescimento: associados à capacidade de aprendizado da instituição e à flexibilidade de fornecer respostas rápidas ao ambiente interno e externo. O modo como a organização define os indicadores e as metas e como analisa seus resultados e disponibiliza as informações prioriza o conhecimento da organização. As informações permitem identificar fraquezas e potencialidades e transformá-los em fontes de vantagem competitiva.

Resultados: identificam o desempenho da organização, para criar valor superior para seus públicos: acionis tas, colaboradores internos e externos, clientes e sociedade. Essa dimensão analisa os resultados de desempenho que envolvem o capital humano, capital ambiental, capital financeiro, processos-chave e clientes.

Fonte: elaborada pelos autores. 
Assim como em outros modelos, as dimensões são subdivididas em atividades-chave, bem como em objetivos específicos, verificados na tabela 3. Desse modo, no modelo proposto, os objetivos estratégicos se estendem por meio das oito dimensões. Em cada dimensão, são identificadas atividades que geram oportunidades para criar sinergias e valor, as quais estão alinhadas com a estratégia da organização. Nesse sentido, o gerenciamento dos planejamentos tático e operacional é indispensável para que os níveis organizacionais possam realizar a mensuração do desempenho e verificar de que modo os resultados alcançados encontram-se alinhados com os objetivos estratégicos previamente definidos.

Tabela 3 - Desdobramento dos objetivos estratégicos

\begin{tabular}{|c|c|c|c|}
\hline Dimensão & Objetivos estratégicos & Sub-dimensão & Objetivos táticos e operacionais \\
\hline Estratégia & $\begin{array}{l}\text { Alcançar nível elevado do ensino - } \\
\text { aprendizado e a sustentabilidade da } \\
\text { IES. }\end{array}$ & Governança corporativa. & $\begin{array}{l}\text { Estabelecer princípios e valores; } \\
\text { melhorar o clima organizacional; } \\
\text { ampliar a comunicação com a sociedade. }\end{array}$ \\
\hline Capital social & $\begin{array}{l}\text { Atuar com respeito e reconhecer o } \\
\text { valor humano na sua amplitude } \\
\text { antropológica, social, cultural e } \\
\text { artística. }\end{array}$ & $\begin{array}{l}\text { Desenvolvimento e } \\
\text { comprometimento dos } \\
\text { profissionais e e ngajamento } \\
\text { com a sociedade. }\end{array}$ & $\begin{array}{l}\text { Elevar o desempenho; melhorar as competências } \\
\text { técnica e dos processos; haver maior } \\
\text { comprometimento do corpo técnico - } \\
\text { administrativo, docentes e discentes. }\end{array}$ \\
\hline Capital ambiental & $\begin{array}{l}\text { Ser reconhecida como instituição } \\
\text { ambientalmente responsável. }\end{array}$ & Gestão ambiental & $\begin{array}{l}\text { Adotar políticas do uso e descarte dos recursos } \\
\text { naturais. }\end{array}$ \\
\hline Capital financeiro & $\begin{array}{l}\text { Atingir a sustentabilidade } \\
\text { econômico-financeira e } \\
\text { aumentar receitas por meio da } \\
\text { criação de novos cursos. }\end{array}$ & Econômico-financeiro. & $\begin{array}{l}\text { Elaborar estudos de viabilidade de investimentos } \\
\text { em infraestrutura; a tuar na racio nalização e } \\
\text { redução dos custos; e levar a margem de } \\
\text { contribuição, lucratividade e ROI. }\end{array}$ \\
\hline Processos-chave & $\begin{array}{l}\text { Aprimorar continuamente a } \\
\text { integração e o desempenho das } \\
\text { atividades-meio e das atividades - } \\
\text { fim. }\end{array}$ & $\begin{array}{l}\text { Organização e gestão } \\
\text { administrativa e } \\
\text { organização e gestão } \\
\text { acadêmica. }\end{array}$ & $\begin{array}{l}\text { Melhorar as atividades e recursos destinados às } \\
\text { atividades-fim; } \\
\text { criar políticas e ampliar ações para o } \\
\text { desempenho do ensino, pesquisa e extensão. }\end{array}$ \\
\hline Clientes & $\begin{array}{l}\text { Elevar e manter permanentemente a } \\
\text { satisfação e o desempenho dos } \\
\text { alunos. }\end{array}$ & $\begin{array}{l}\text { Formação acadêmica e } \\
\text { desempenho no Enade. }\end{array}$ & $\begin{array}{l}\text { Atrair e reter alunos; melhorar o desempenho do } \\
\text { corpo docente; o ferecer oportunidades de } \\
\text { desenvolvimento profissional ; a Icançar nível } \\
\text { elevado no processo de avaliação do Enade. }\end{array}$ \\
\hline $\begin{array}{l}\text { Aprendizagem e } \\
\text { crescimento }\end{array}$ & $\begin{array}{l}\text { Avaliar o desempenho } \\
\text { organizacional e gerencia r } \\
\text { informações visando a } \\
\text { aprendizagem e crescimento da } \\
\text { organização. }\end{array}$ & $\begin{array}{l}\text { Desempenho } \\
\text { organizacional, } \\
\text { informação e } \\
\text { aprendizagem. }\end{array}$ & $\begin{array}{l}\text { Gerenciar os procedimentos de revisão dos } \\
\text { indicadores e das ações de melhoria ; a tuar na } \\
\text { disseminação do conhecimento e crescimento } \\
\text { organizacional. }\end{array}$ \\
\hline Resultados & $\begin{array}{l}\text { Avaliar continuamente os resultados } \\
\text { das perspectivas anteriores, com } \\
\text { enfoque nas atividades -chave, para } \\
\text { oferta de valor superior dos serviços. }\end{array}$ & $\begin{array}{l}\text { Resultado: liderança; } \\
\text { Resultado: social; } \\
\text { Resultado: ambiental; } \\
\text { Resultado: financeiro; } \\
\text { Resultado: processos; } \\
\text { Resultado: com cliente. }\end{array}$ & $\begin{array}{l}\text { Escolher os indicadores de resultados-chave, } \\
\text { como, por exemplo: indicadores financeiros, } \\
\text { grau de satisfação dos alunos, conceitos } \\
\text { Sinaes/MEC, ENADE/CPC/IGC e Cl. }\end{array}$ \\
\hline
\end{tabular}

Fonte: elaborada pelos autores.

O desdobramento da estratégia se inicia a partir da dimensão "Estratégia". A relação de causa e efeito do desempenho não está vinculada a apenas uma dimensão ou setor, mas está inserida, de modo interligado e holístico, ou seja, envolve todos os processos desenvolvidos. A representação gráfica da estratégia da organização é concebida pelo mapa estratégico, que tem a função de mostrar a perspectiva do sistema de gestão. Para os propósitos deste estudo, são sugeridos alguns indicadores, os quais devem ser associados aos objetivos de cada uma das dimensões, conforme exposto na figura 8. 


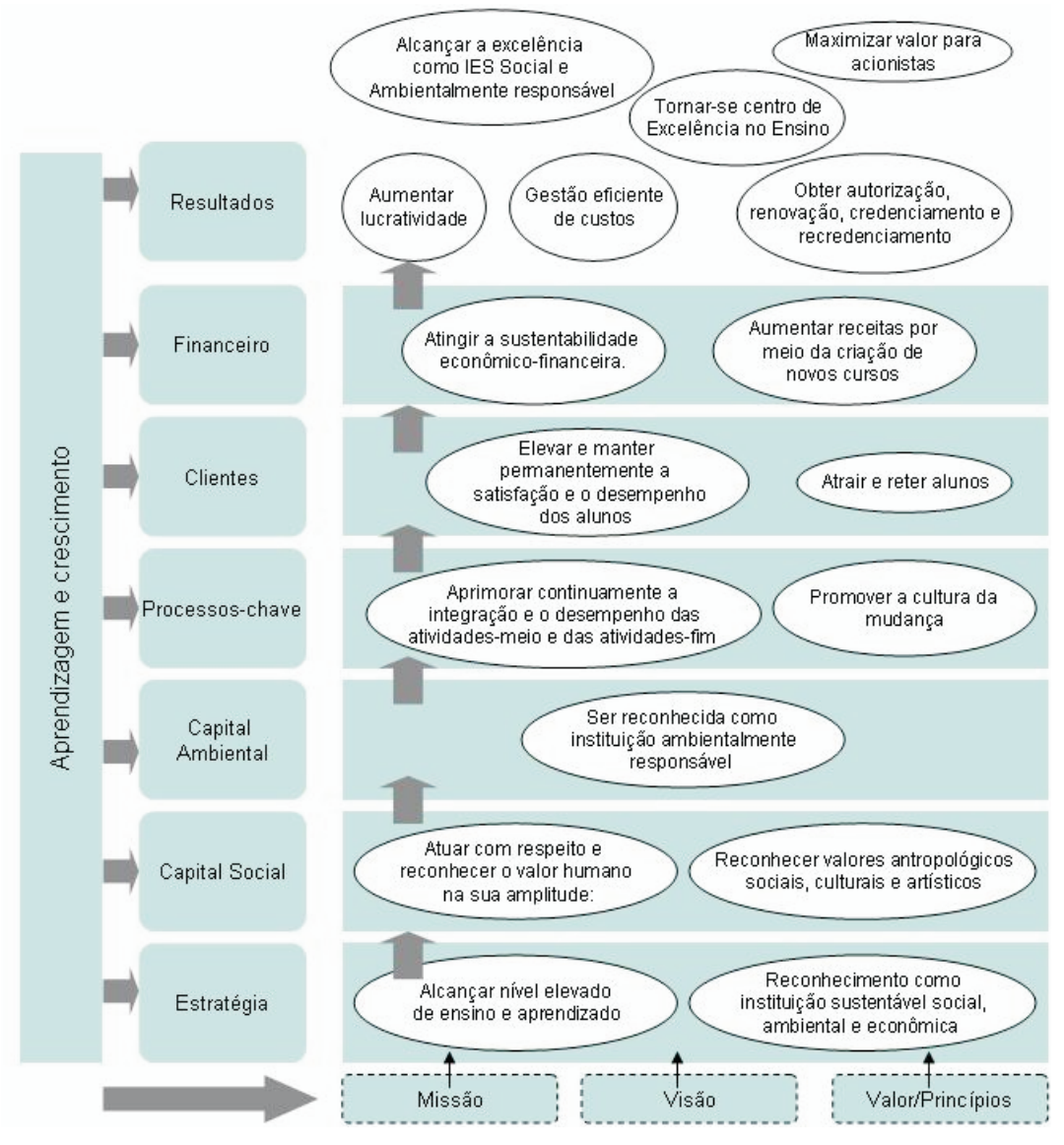

Figura 8 - Mapa estratégico

Fonte: elaborada pelos autores.

O mapa estratégico permite analisar criticamente como o desempenho ocorre, ou seja, o instrumento avalia como o sistema de mensuração do desempenho global da organização se comporta em termos dos vetores de desempenho e de resultados. Após a exemplificação dos desdobramentos da estratégia e a definição dos objetivos, é necessário definir os indicadores de desempenho e de tendência. O sistema parte da concepção do Plano de Desenvolvimento Institucional (PDI), Projeto Pedagógico da Instituição (PPI) e Regimento Interno (RI). O PDI contempla a formulação da visão, da missão, dos objetivos e das metas que a IES almeja, como, por exemplo, investimentos em infraestrutura e expansão de novos cursos. O PPI define critérios de envolvimento, integração e articulação referentes aos aspectos pedagógicos e de importância social, associados ao ensino, à pesquisa e à extensão, tanto para as universidades como para os centros universitários, faculdades integradas e faculdades isoladas. O programa político administrativo-pedagógico tem como base o Rl, que define o conjunto de normas para regular e orientar o funcionamento e o desenvolvimento da organização.

Em síntese, o mapa estratégico estabelece a relação dos objetivos fixados em cada dimensão e determina a relação de causa e efeito. Além disso, os indicadores de desempenho devem oferecer informações essenciais para nortear os responsáveis por possíveis desvios quanto aos objetivos almejados no planejamento estratégico da IES. Esse processo não é simples; sugere-se a formação de equipe de trabalho específica, nomeada pela direção da IES. O grupo analisará desde a etapa inicial da concepção do PDI e PPI até a formulação dos indicadores e metas de verificação do desempenho, conforme sugerido na tabela 4. 
Tabela 4 - Indicadores de desempenho e de tendência

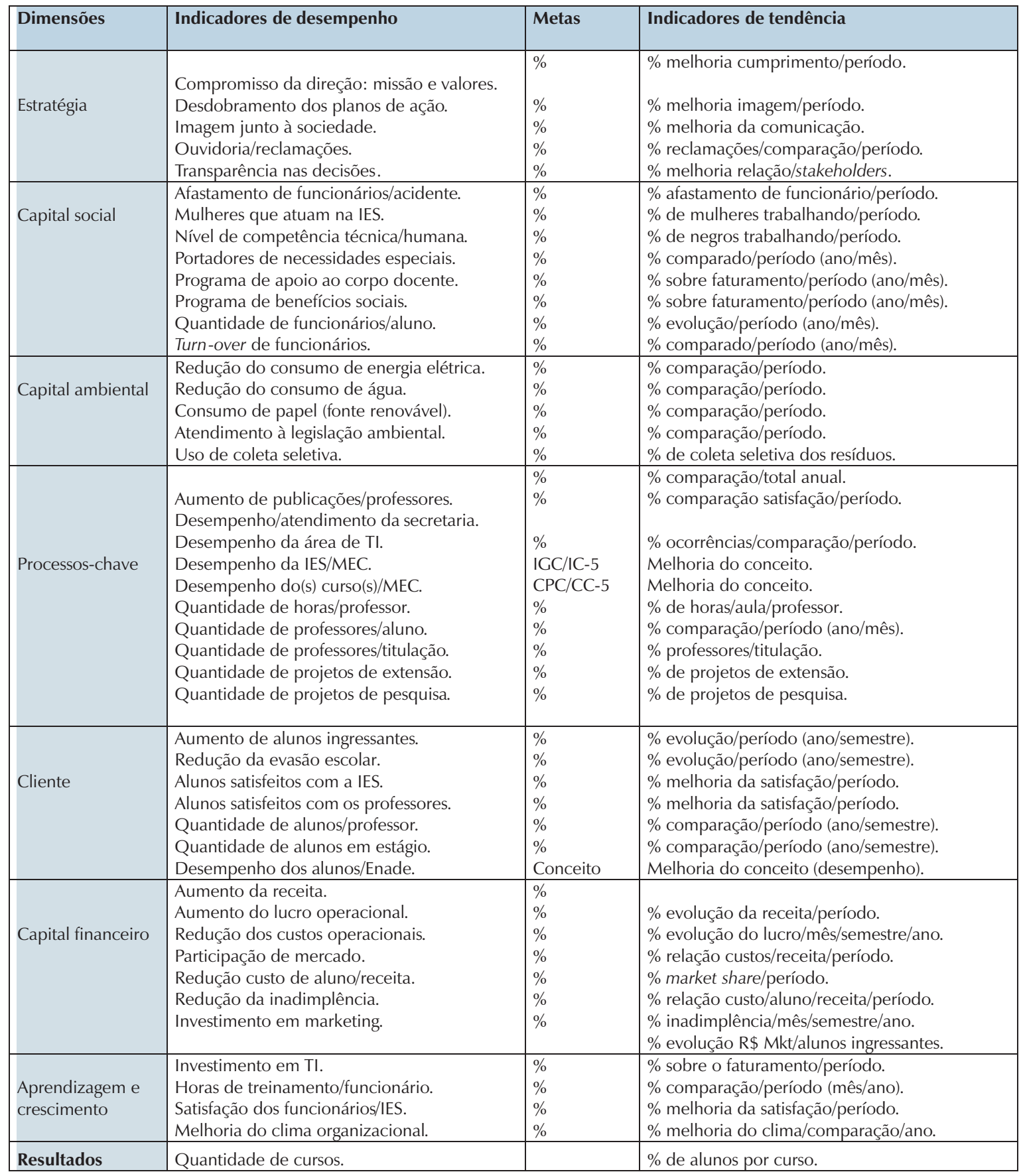

Fonte: elaborada pelos autores.

O conjunto dos indicadores apresentados pode ser enriquecido com vários outros indicadores. A escolha depende dos objetivos estratégicos e das necessidades que variam entre as organizações. Este modelo fixou objetivos relacionados com o "social" e "ambiental", contribuições do modelo Sigma Sustainbility. Conforme Tachizawa e Andrade (2006), o papel dos gestores é crucial para definir e implementar a estratégia e garantir a sinergia para o cumprimento dos objetivos e metas entre os vários níveis da estrutura organizacional. Desse modo, a configuração dos indicadores para as IES está sujeita à amplitude de atuação fixada na estraté- 
gia. Para determinadas instituições, pode ser determinante o desenvolvimento de projetos sociais e ambientais ligados, por exemplo, às organizações do terceiro setor, às cooperativas de reciclagem ou aos programas de educação ambiental em parceria com as empresas.

Por outro lado, o delineamento dos indicadores de desempenho e de tendência e as respectivas metas podem variar conforme o grau de importância ou na medida em que os objetivos estratégicos são excluídos ou substituídos. Cabe destacar a importância de nomear profissionais responsáveis em monitorar o cumprimento das metas de desempenho e com competência para estabelecer planos de ação. O sistema de avaliação de desempenho global é um poderoso instrumento de gestão para a IES. Concomitantemente, os gestores podem utilizar a ferramenta PDCA (planejar, fazer, verificar e aperfeiçoar), principalmente para o aperfeiçoamento do modelo. Esse aspecto justifica o fato de que os modelos de avaliação de desempenho fundamentados neste estudo, inclusive o modelo proposto, não têm caráter prescritivo e, portanto, são dotados de flexibilidade e abordagem sistêmica.

\section{CONSIDERAÇÕES FINAIS}

Como ocorre em outros setores, as instituições de ensino superior também precisam cumprir metas que visem o alcance de objetivos da própria organização e, especialmente, que atendam a exigências legais fixadas pelo Sinaes e conduzidas pela Conaes. Os aspectos ambientais que envolvem governo, sociedade, empresas e concorrentes, assim como o atendimento das necessidades de seus clientes e a garantia de um bom ambiente de trabalho, são determinantes para a sobrevivência das organizações. Desse modo, a utilização dos objetivos estratégicos estimula a organização para a busca de melhores resultados. Por outro lado, é necessário fixar medidas de desempenho e avaliar os resultados alcançados. A melhoria do desempenho organizacional só é possível quando se consegue medir diferentes dimensões ou perspectivas.

A execução de um sistema de avaliação de desempenho global demanda empenho da direção, cujos membros, geralmente, estão vinculados a uma mantenedora. O modelo de avaliação global ora proposto caracteriza-se como uma versão sintética. Apesar de aparentemente simples, seu uso se torna mais complexo para as IES com estrutura diversificada e com mais de um campus, como é o caso das universidades e dos centros universitários. Apesar de as faculdades integradas e faculdades isoladas possuírem, aparentemente, estruturas menos diversificadas, ainda assim a condução de um sistema de avaliação de desempenho global exige cautela, e não se pode crer que tragam soluções rápidas para todos os problemas que surgirem. Nesse sentido, este estudo submeteu um modelo de avaliação de desempenho global compatível para atender às exigências legais do MEC/Sinaes, bem como para contribuir para o desenvolvimento de novos estudos e modelos, visando a melhoria da gestão das instituições de ensino superior no Brasil.

\section{REFERÊNCIAS BIBLIOGRÁFICAS}

\section{BNQP - Baldrige National Quality Program, 2010. Disponível em: <http:// www.quality.nist.gov $>$. Acesso em: 15 maio 2010.}

BOWERSOX, D. J.; CLOSS, D. J. Logística empresarial: o processo de integração da cadeia de suprimentos. São Paulo: Atlas, 2001.
BRASIL. Ministério da Educação. Avaliação externa de instituições de educação superior: diretrizes e instrumento. Brasília: MEC, nov. 2005.

BRASIL. Ministério da Educação. Instituto de Estudos e Pesquisas Educacionais Anísio Teixeira (Inep). O conceito preliminar de curso e o índice geral de cursos. Disponível em: <http://www.inep.gov.br/institucional/ faq_inep.htm>. Acesso em: 26 jun. 2010. 
BRASIL. Ministério da Educação. Sistema Nacional de Avaliação da Educação Supe-

rior - Sinaes: da concepção à regulação. 5. ed. rev. ampl.Brasília: MEC, set. 2009.

CORRÊA, L. H. Modelo de avaliação de desempenho organizacional: MADE-O - como conhecer o verdadeiro desempenho de uma organização. São Paulo: Programa de Pós-Graduação da FEA-USP, 2010. (Texto científico para estudo na disciplina EAD-5948 - Avaliação de Desempenho Global.)

CUNHA, J. A. C. da; CORRÊA, H. L.; CALEGARI, F. L. O balanced scorecard e a avaliação de inovações: as problemáticas dos paradoxos de inovação e de produtividade. In: SEMEAD, 10. Anais... 2007. Disponível em: <http://www.ead.fea.usp.br/semead/ 10semead>. Acesso em: 18 maio 2010.

DRUCKER, P. F. Os novos paradigmas da administração. Revista Exame, São Paulo, p. 74, fev. 1999.

EFQM - European Foundation for Quality Management, 2010. Disponível em: <http:// www.efqm.org >. Acesso em: 17 maio 2010.

\section{FNQ - Fundação Nacional da Qualidade,} 2010. Disponível em <http:// www.fnq.org.br>. Acesso em: 20 abr. 2010.

HOURNEAUX JR., F.; CORRÊA, H. L. A influência do fator humano na mensuração e avaliação do desempenho organizacional: estudo de casos no setor químico no Brasil. In: ENANPAD, 2007, Rio de Janeiro. Anais... Rio de Janeiro: 2007. Disponível em: <http:// w w w a $n$ p a d. o r g b r / evento.php? acao $=$ trabalho \& co

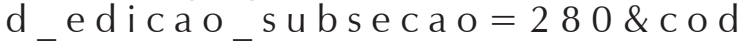
evento edicāo $=33 \&$ cod edicao trabalho =7175 ${ }^{-}$. Acesso em: 17 máio $201 \overline{0}$.
HOURNEAUX JR., F.; CUNHA, N. C. V. da; CORRÊA, H. L. A importância da inovação na utilização do balanced scorecard nas organizações: um estudo de caso. Puerto Plata: Cladea/Pontifícia Universidad Católica Madre y Maestra, 2004. (Texto científico para estudo na disciplina EAD-5948 - Avaliação de Desempenho Global. Programa de Pós-Graduação da FEA-USP, São Paulo, 2010.)

KAPLAN, R. S.; NORTON, D. P. Alinhamento: utilizando o balanced scorecard para criar sinergias corporativas. 2. ed. Rio de Janeiro: Elsevier, 2006.

MAÑAS, A. V. Gestão de tecnologia e inovação. São Paulo: Érica, 1993.

Nist - National Institute of Standards na Technology, 2010. Disponível em: <http:// www.nist.gov/baldrige/>. Acesso em: 30 abr. 2010.

Sigma - Projeto Sigma, 2010. Disponível em: $<$ www.projectsigma.co.uk/Guidelines/ SigmaGuidelines.pdf $>$. Acesso em: 11 jun. 2010.

TACHIZAWA, T.; ANDRADE, R. O. B. Gestão de instituições de ensino. 4. ed. Rio de Janeiro: FGV, 2006.

WHITELEY, R. A empresa totalmente voltada para o cliente. Rio de Janeiro: Campus, 1999.

YOKOMIZO, C. A. Avaliação de desempenho organizacional: um estudo exploratório em empresas brasileiras de desenvolvimento de software. 2009. 165f. Dissertação (Mestrado em Administração) - Universidade do Estado de São Paulo, São Paulo, 2009. Disponível em: $<$ http://www.teses.usp.br/index >. Acesso em: 21 maio 2010. 